\title{
Erratum: Psychiatric consultations and the management of associated comorbid medical conditions in a regional referral hospital
}

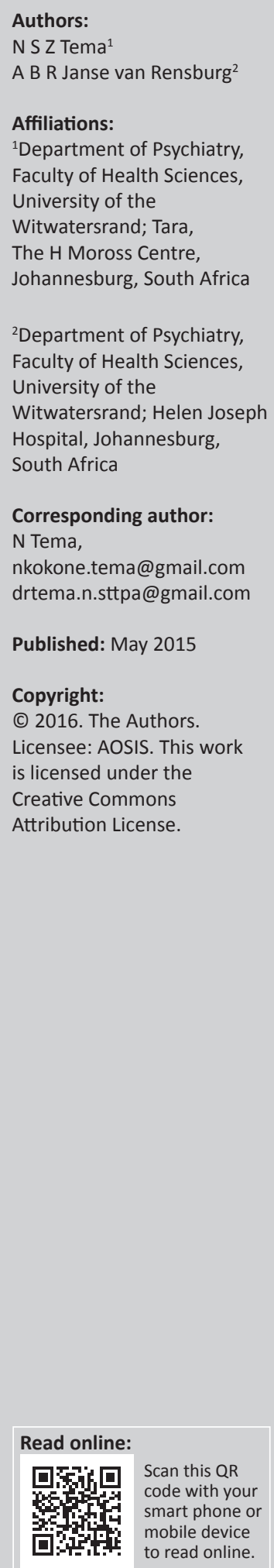

This article was erroneously published in 2015 under the DOI citation S Afr J Psychiatr 2015;22(2) instead of the correct S Afr J Psychiatr 2015;21(2). 